Bucknell University

Bucknell Digital Commons

Faculty Journal Articles

Faculty Scholarship

2017

\title{
Testing a theory of sense of community and community responsibility in organizations: An empirical assessment of predictive capacity on employee well-being and organizational citizenship.
}

Neil Boyd

Bucknell University, nmb015@bucknell.edu

Branda Nowell

North Carolina State University, branda_nowell@ncsu.edu

Follow this and additional works at: https://digitalcommons.bucknell.edu/fac_journ

Part of the Community Psychology Commons, Human Resources Management Commons, Organizational Behavior and Theory Commons, and the Public Affairs, Public Policy and Public Administration Commons

\section{Recommended Citation}

Boyd, Neil and Nowell, Branda. "Testing a theory of sense of community and community responsibility in organizations: An empirical assessment of predictive capacity on employee well-being and organizational citizenship.." Journal of Community Psychology (2017) : 210-229.

This Article is brought to you for free and open access by the Faculty Scholarship at Bucknell Digital Commons. It has been accepted for inclusion in Faculty Journal Articles by an authorized administrator of Bucknell Digital Commons. For more information, please contact dcadmin@bucknell.edu. 


\section{TESTING A THEORY OF SENSE OF COMMUNITY AND COMMUNITY RESPONSIBILITY IN ORGANIZATIONS: AN EMPIRICAL ASSESSMENT OF PREDICTIVE CAPACITY ON EMPLOYEE WELL-BEING AND ORGANIZATIONAL CITIZENSHIP}

Neil M. Boyd

Bucknell University

Branda Nowell

North Carolina State University

This study attempts to advance our understanding of the experience of community in organizational settings by empirically testing a theory of sense of community responsibility $(S O C-R)$ in relation to traditional measures of sense of community [SOC] on outcomes of employee well-being and organizational citizenship. Findings support the notion that SOC is a better predictor of employee well-being, while SOC-R more strongly predicts organizational citizenship behavior. The findings add new knowledge to the literature on the experience of community in organizations, as well as representing an important contribution to our understanding of the factors that drive employee action and well-being at work. (C) 2017 Wiley

Periodicals, Inc.

Community psychologists have long recognized the workplace as an important community space (Klein \& D’Aunno 1986; Burroughs \& Eby 1998; Chioneso \& Brookins 2013;

Please address correspondence to: Neil Boyd, Professor of Management, C. Graydon and Mary E. Rogers Faculty Fellow, School of Management, Bucknell University, Lewisburg, Pennsylvania 17837. E-mail: Neil.Boyd@Bucknell.edu 
Pretty \& McCarthy 1991; Royal \& Rossi 1996; Speer et al. 2013; Zani \& Cicognani 2012). More recently, organizational scholars have likewise devoted increasing attention to the topic of developing communities in organizational settings. Perhaps the most prominent examples of popular press scholarship are contained in the writings of Mintzberg (2009) and Block (2008), which provided a landscape for managers to consider creating communities at work. For example, Mintzberg noted that successful organizations usually have a sense of community, and Block (2008) proposed that we need to consider developing an authentic sense of community in institutional settings.

In the recent peer-reviewed literature, there is a growing consensus that communityoriented constructs are value-added in organizational settings (Barczak, Smith, \& Wilemon, 1987; Brytting \& Trollestad, 2000; Cunha, Rego, \& Vaccaro, 2014; Dessler 1999; McBride 2006; Milliman, Czaplewski, \& Ferguson, 2003; Rego \& Cunha 2007; Rego, Cunha, \& Souto, 2007; Rowley, Kupiec-Teaham, \& Leeming 2007). Notable among this work is Kets de Vries (2001), who suggested that healthy organizations include a sense of belonging, a sense of community, and a preparedness to help others. In addition, a number of scholars proposed that a sense of connection and community is a key dimension of spirituality at work (e.g., see Ashmos \& Duchon, 2000; Milliman et al. 2003), and empirically, Rego and Cunha (2008) showed that spirituality at work correlated to organizational commitment. Their findings provided a platform for the argument that spirituality (with the dimension of team's sense of community) can potentially produce effects on factors like commitment, employee well-being, organizational citizenship behaviors, performance, and ultimately organizational-level factors that improve the longevity and health of the firm.

Despite the growth of commentary on the role and importance of community in the workplace in the literature to date, empirical studies are scarce (for review, see Boyd, 2014). As such, there is limited theoretical and empirical knowledge available to propel a specific research agenda of community at work forward. The present study seeks to address this gap, examining the relative contribution of two aspects of community experience: sense of community (SOC) and sense of community responsibility (SOC-R) in relation to employee well-being and organizational citizenship. In doing so, this study aims to both advance our understanding of the role of community experience in a single organizational setting and test theoretical propositions on the relative contributions of resource versus responsibility aspects of community experience as put forth by Nowell and Boyd (2011, 2014).

\section{SOC and SOC-R in Organizations}

One theoretical model that has particular promise for application in organizational contexts is the community experience framework developed by Nowell and Boyd (2010, 2014). As Nowell and Boyd (2010) articulated (see bottom of Figure 1), traditional measures of SOC tend to reflect an individual's sense that their community serves as a resource for meeting key physiological and psychological needs such as the need for affiliation, influence, and connection (e.g., see the Sense of Community Index (Perkins, Florin, Rich, Wandersman, \& Chavis, 1990), the Sense of Community Index-2 (Chavis, Lee, \& Acosta, 2008), and the Brief Sense of Community Scale (Peterson, Speer, \& McMillan, 2008).

They noted that a SOC should be positively related to community engagement and personal well-being. Significant empirical support across a variety of community settings backs up this proposition (Brodsky, O’Campo, \& Aronson, 1999; Miers \& Fisher, 2002; Obst, Zinkiewicz, \& Smith, 2002; Perkins et al., 1990; Pretty, 1990; Sonn, 2002). For 


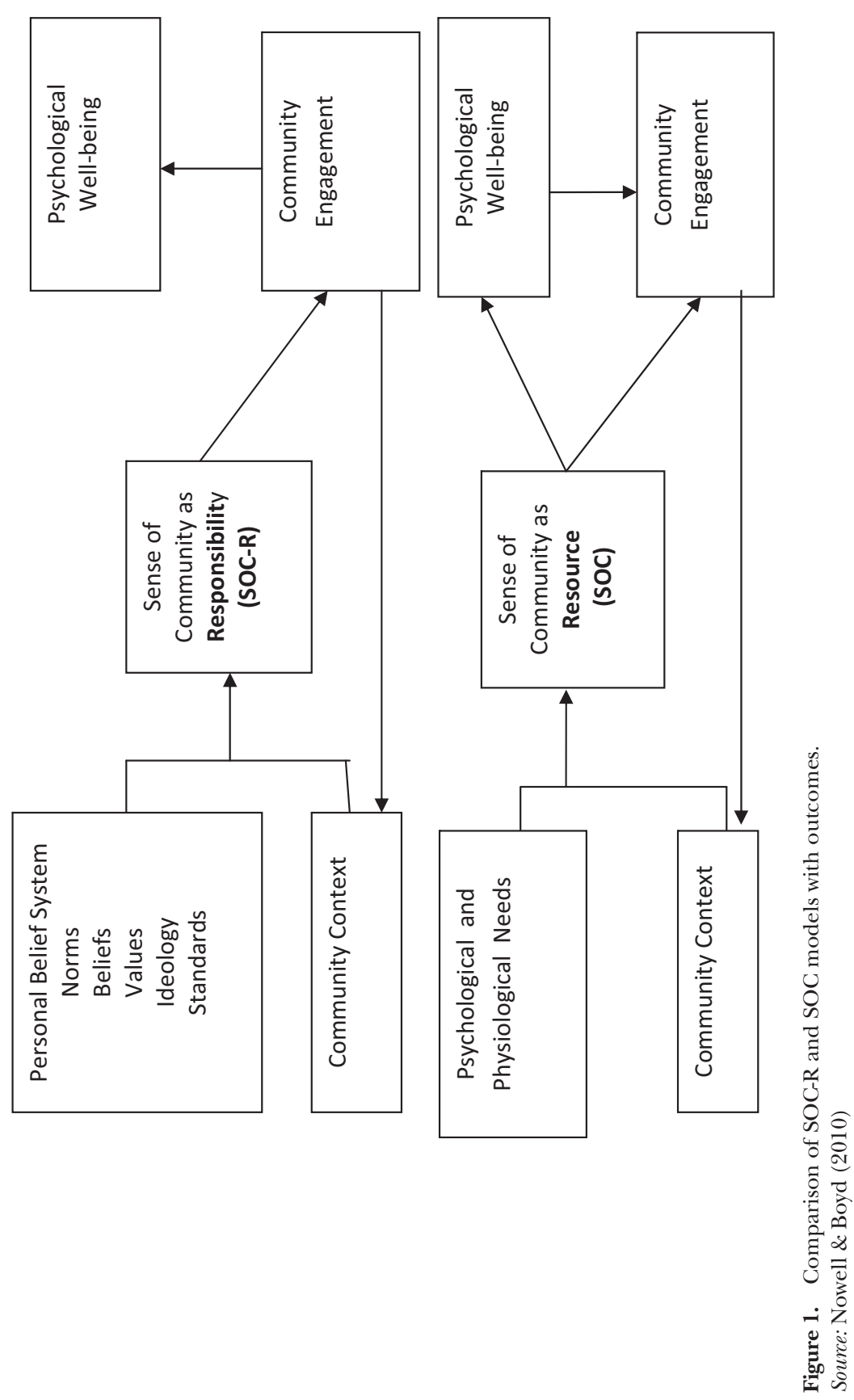


example, SOC has been found to predict outcomes like psychological well-being (Davidson \& Cotter, 1991; Peterson, Speer, \& McMillan, 2008; Pretty et al., 1996; Prezza \& Pacilli, 2007), as well as community engagement, political participation, and civic involvement (Albanesi, Cicognani, \& Zani, 2007; Brodsky, O'Campo, \& Aronson, 1999, Hughey, Speer \& Peterson, 1999; Peterson et al., 2008; Prezza, Pacilli, Barbaranelli, \& Zampatt, 2009).

Nowell and Boyd (2010) proposed SOC-R as complementary to SOC, arguing that it represented a different and undertheorized aspect of experiencing community. They define SOC-R as a feeling of duty or obligation to protect or enhance the well-being of a group and its members. It is distinguished from traditional measures of SOC in its emphasis on feelings of obligation to a community rather than perceptions of what one gets from a community. SOC-R theorizes that individuals develop personal values, norms, ideals, and beliefs through being embedded in various institutions (e.g., families, churches, schools, neighborhoods, social groups) that they carry with them into new settings (see top of Figure 1). These a priori belief structures interact with specific aspects of a given setting and, in some cases, can evoke sentiments of duty and obligation for individuals as they seek to reconcile who they perceive they are in a given setting and their normative beliefs about what a person like them should do in such a setting. Once developed, SOC-R perceptions are posited to increase engagement in that setting (Nowell \& Boyd, 2010, 2014; Boyd \& Nowell, 2014).

The community experience framework further posits that SOC and SOC-R will have differential effects. SOC, with its emphasis on community as a resource for meeting one's needs, is hypothesized to be the stronger predictor of indicators related to psychological happiness and well-being. However, the relationship of SOC to community engagement is theorized to be more attenuated for SOC because, according to the underlying model, SOC would drive engagement to the extent that individuals felt that such engagement would ultimately increase needs fulfillment. Conversely, Nowell and Boyd (2010) posit that SOC-R, with its emphasis on the desire to create psychological congruence between identity and behavior, will have a relatively stronger direct effect on engagement with a community relative to SOC. At the same time, the dissonance that is theorized to drive behavior in SOC-R is likely to have an attenuated relationship to happiness and well-being, likely mediated through engagement efforts.

Preliminary support for the basic propositions of Nowell and Boyd's resource and responsibility framework was found by Nowell and Boyd (2014) in a recent study that looked at both SOC and SOC-R in the context of community collaboratives. They empirically demonstrated that resource versus responsibility experiences of community were unique constructs to each other, and they showed discriminant validity between each other on measures of satisfaction with the group and engagement in leadership action within a collaborative network setting. In particular, the findings demonstrated that SOC was the strongest predictor of general satisfaction, whereas SOC-R was the stronger predictor of higher order engagement and uniquely predicted leadership. Finally, this work, in conjunction with theoretical justifications for construct distinction (Boyd \& Nowell, 2014), has helped to clarify that SOC-R is different from related organizational constructs with more general referents (e.g., organizational commitment and identity), and "other regarding" constructs like civic engagement, social responsibility, and public service motivation, because SOC-R describes the unique relationship of an individual to a specific community in which they are embedded. Other prosocial constructs are not designed with such context-specific referents.

Because empirical research on community experiences at work is in its infancy, we believe it is important to continue to both determine that SOC-R is empirically distinct 
from SOC and test and refine the ability of these constructs to produce discriminant validity on criteria of interest. In this case, we focus specifically on two outcomes of concern to the field: employee psychological well-being and organizational citizenship. Psychological well-being is a construct of obvious interest to the field of community psychology because improving the human condition is core to the values of our field. Given that humans spend a considerable portion of their lives in "organizational communities" (Boyd \& Angelique, 2002), understanding how community experiences at work influence well-being is a pertinent question.

Organizational citizenship should also be of interest to community psychologists because of its focus on "extra role" behavior. It has been defined as "individual behavior that is discretionary, not directly or explicitly recognized by the formal reward system, and that in the aggregate promotes the effective functioning of the organization" (Organ, 1988, p. 4). As Williams and Anderson (1991) note, organizational citizenship behaviors (OCBs) can be directed toward individuals (OCBIs) or the organization as a whole (OCBOs). Together, OCBIs and OCBOs represent engagement in helping behaviors toward others and the organizational entity as a collective.

As Podsakoff et al, (2009) mention in a recent meta-analysis of OCB, "one of the main reasons for the interest in OCBs is that they are expected to be positively related to measures of organizational effectiveness" ( $p$ 122). Their study found support for this premise, indicating that OCBs are related to individual-level outcomes (e.g., managerial ratings of employee performance, allocation of rewards), withdrawal-related measures (e.g., employee turnover intentions, actual turnover, and absenteeism), and organizational-level outcomes (e.g., productivity, efficiency, reduced costs, customer satisfaction, and unitlevel turnover). Therefore, understanding how SOC and SOC-R predict OCBs may have important implications for understanding mechanisms that produce additional key individual and organizational outcomes. However, despite significant theoretical justification to suggest the psychological experience of community would be critical to understanding employee well-being and organizational citizenship, no studies have investigated these relationships to date.

\section{Testing SOC Versus SOC-R}

As noted earlier, one empirical study has been conducted to test the Nowell and Boyd (2010) community experience framework and the findings were consistent with the theoretical propositions of the model. In their study of a collaborative public health network (Nowell \& Boyd, 2014), SOC and SOC-R were found to be related yet unique constructs. We will attempt to replicate this finding by proposing the following hypothesis:

H1: SOC will be a related but unique construct relative to SOC-R.

In addition, we test the core propositions of Nowell and Boyd's (2010, 2014) community experience framework. Specifically, the following hypotheses are proposed:

H2: SOC will be a stronger predictor of psychological well-being relative to SOC-R.

H3: SOC-R will be a stronger predictor of OCBs relative to SOC.

Research has found preliminary support for this latter hypothesis (e.g., Nowell \& Boyd, 2014), but it is important to note that some recent studies also support the inverse hypothesis. Specifically, studies have shown that employees adopt more OCBs for reciprocating (e.g., see Coyle-Shapiro, 2002; Organ \& Paine, 1999) toward their organizations and leaders. Thus, counter to our hypothesis, it is plausible that employees might adopt 
more OCBs as a way to reciprocate toward an organization that provides resources to them. If $\mathrm{OCB}$ is driven more by dynamics of reciprocity, rather than responsibility, then the resource-oriented SOC may prove to be a stronger predictor of OCBs.

Finally, the present study also seeks to expand upon existing research by testing mediation and moderation effects that are potentially present in the community experience framework (Nowell \& Boyd, 2010). Because the model does not identify if mediation or moderation will occur, an exploratory empirical assessment will be conducted on these types of effects. SOC is expected to predict both psychological well-being and community engagement behaviors. However, for individuals with high SOC, OCBs might also occur as a function of an employees' psychological well-being. For example, as affiliation, influence, and connection needs are fulfilled, the employee may feel improved psychological well-being, which in turn could increase the probability that the employee will subsequently take action to improve the well-being of the organizational community.

Therefore, the following exploratory hypotheses are proposed:

H4a: The relationship between SOC and OCBs will be mediated by psychological wellbeing.

H4b: The relationship between SOC and OCBs will be moderated by psychological well-being.

Within the SOC-R model, a direct relationship between well-being and SOC-R cannot be assumed because it is most likely mediated or moderated by community engagement. As Nowell and Boyd (2010) noted, the indirect relationship between SOC as responsibility and well-being is consistent with cognitive dissonance theory (Festinger, 1964) because inaction on the part of the individual creates an uncomfortable psychological state that the person seeks to ameliorate. To resolve the dissonance, one can either fit one's behavior to be in line with one's attitudes or change one's attitudes to be in line with one's behavior. Dissonance theory relies on the premise that alignment between what a person believes and values and how they act contributes to positive mental well-being. Thus, the relationship between SOC-R and psychological well-being will likely be mediated or moderated by OCBs.

Therefore, the following exploratory hypotheses are proposed:

H5a: The relationship between SOC-R and psychological well-being will be mediated by OCBs.

H5b: The relationship between SOC-R and psychological well-being will be moderated by OCBs.

A final goal of the study is to investigate if the findings of Nowell and Boyd (2014) can be extended into a single organizational context. Commentary on the replication of this issue will be provided in the discussion section. In summary, the present study aims to advance our understanding of (a) the uniqueness of SOC versus SOC-R and (b) the predictive capacity of SOC and SOC-R on untested measures of psychological well-being and community engagement, as well as (c) extending our knowledge of how members experience and engage in organizational settings.

\section{METHOD}

\section{Sample and Procedures}

The study was conducted in a large healthcare system in the Eastern United States. A survey was administered to all employees via an e-mail, which was sent by a representative 
of the human resources department. At the request of the human resources department, the study concluded after one reminder. A total of 1,522 employees received the e-mail prompt; we obtained complete data for all items collected from 369 subjects $(24.24 \%$ response rate). This response rate is consistent with those found in organizational survey studies, and is this is especially true in settings where response-enhancing techniques are minimized by formal administrative structures or rules (Anseel, Lievens, Schollaert, \& Choragwicka, 2010). However, driven by concerns over selection bias, we ran a series of comparative analyses aimed at investigating systematic differences in demographics between our respondent sample and the sample population. Analysis failed to find significant differences on full-time and part-time status, gender, race, education, organizational tenure, or organizational role (all $p \mathrm{~s}>.05$ ). We are therefore confident that our resulting sample is representative of our sample population.

Of the participants, $93 \%$ were full-time employees, $83.2 \%$ were female, and $97 \%$ were Caucasian (all others $<1 \%$ ). Participants ranged in educational levels from high school diplomas to doctorate degrees (high school diploma, 21.5\%; associate's, 25.3\%; bachelor's, $33.7 \%$; master's, $15.4 \%$; $\mathrm{PhD} / \mathrm{JD} / \mathrm{MD}, 4.1 \%$ ), and on average they were employed for 14.83 years (standard deviation $[S D]=11.77 ; \mathrm{min} / \mathrm{max}, 1 / 45$ ). The majority of participants were project and program staff members $(67.4 \%)$ or midlevel administrators $(24.2 \%)$, while fewer respondents were directors or head administrators in the system $(8.4 \%)$.

\section{Measures}

SOC as resource. The Brief Sense of Community Scale (BSCS; see Peterson, Speer, McMillan, 2008) measured SOC. The BSCS normally uses the referent of a neighborhood, and thus the scale was modified so all items referenced the respondent's organization or members of the organization. A 7-point Likert-type response option format ranging from 1 (strongly agree) to 7 (strongly disagree) was used for all items (e.g., "My organization helps me meet my goals"). Cronbach's alpha for SOC was .936.

SOC-R. A six-item scale, previously developed and used by Nowell and Boyd (2014), with modifications to the referent (i.e., an organization and co-workers) measured SOC-R. All SOC-R items used a 7-point Likert-type response option format ranging from 1 (strongly agree) to 7 (strongly disagree) (e.g., "I am always ready to help out people in my organization even if it creates hardship for me"). Cronbach's alpha for SOC-R was .819.

OCBS. The Organizational Citizenship Scale, developed by Williams and Anderson (1991), measured OCBs. Seven items measured OCBI (e.g., "I help others who have heavy workloads," "I take time to listen to co-workers problems and worries," "I go out of my way to help new employees"), and seven items measured OCBO (e.g., "I conserve and protect organizational property," "I adhere to informal rules designed to maintain order," "I take undeserved work breaks") All items were measured on a 7-point Likert-type scale ranging from 1 (strongly agree) to 7 (strongly disagree). Cronbach's alpha was .817 for OCBI items and .706 for OCBO items.

Psychological well-being. The 12-item General Health Questionnaire (GHQ-12; Goldberg \& Williams 1988; Lesage, Martens-Resende, Deschamps, \& Berjot, 2011) measured psychological well-being. The GHQ-12 is a self-report measure of psychological morbidity, intended to detect psychiatric disorders in community settings and nonpsychiatric 
contexts. The GHQ-12 is a well-known instrument for measuring minor psychological distress, and it tends to be more useful when adapted in a work context serving as a general indicator of distress and/or potential problems. Items included statements like, "I have been feeling unhappy and depressed," "I am able to concentrate," "I am able to enjoy day-to-day activities," and "I feel that I can't overcome difficulties." Cronbach's alpha was .882 for the GHQ-12 scale.

\section{Item and Factor Structure}

A confirmatory factor analysis (CFA) in IBM SPSS Amos (version 21) was conducted to validate the item structure for each of the measures, determine if factors were structurally unique, and rule out potential problems with common-method bias. In relation to this latter issue, Podsakoff, MacKenzie, Lee, and Podsakoff (2003) note several procedural remedies to common-method concerns, including measuring the predictor and criterion factors from different sources or at different times. They also note that these methods often cannot be completed because they require a linking procedure between the measures that can compromise anonymity. We were not able to execute either method because the healthcare system imposed constraints on these techniques due to serious concerns of respondent anonymity. However, we were able to implement other procedural remedies that Podsakoff et al. (2003) suggest, including counterbalancing question order and refining scale items (e.g., we used validated scales, concise item construction, avoided double barrels, and used different scale endpoints).

Moreover, we ran a statistical remedy for potential common-method bias. First, a CFA was computed with each of the five latent factors and their corresponding items. The CFA measurement model showed that items loaded significantly onto their respective factors (see Table 1) and an overall examination of indices showed acceptable model fit: root mean square error of approximation (RMSEA) $=.048$, comparative fit index (CFI) $=$ .912 , incremental fit index $(\mathrm{IFI})=.902$. The findings revealed that items appropriately loaded on each of the measures and all factors were structurally unique.

Next, a second CFA was computed with a common latent factor linked to every item across all scales and to each of the five latent factors and their corresponding items. The change in standardized regression estimates was computed, and three of the items for the SOC scale were found to significantly deviate $(>.2)$ from the original model. No other items for any variables showed significant changes in standardized regression estimates. The second CFA measurement model showed that items loaded significantly onto their respective factors (see Table 1) and overall examination of indices showed acceptable model fit: RMSEA $=.049$, CFI $=.909$, IFI $=.904$. The findings revealed that items appropriately loaded on each of the measures and all factors were structurally unique. Results of hypothesis testing that are presented next all used the common method bias adjusted composites that were produced in the second CFA.

\section{RESULTS}

Descriptive statistics and Pearson correlations were analyzed for all major variables in the study and they are presented in Table 2 .

The analysis revealed that respondents reported above-average perceptions of both SOC and SOC-R. This finding suggests that the organization was perceived to fulfill specific needs of respondents, and that it represents a community setting for which employees 
Table 1. CFA Measurement Model Structure of all Variables in the Study

Factor 1-Sense of Community (SOC)

My organization helps me meet my goals.

I can get what I need from this organization

I feel like a member of my organization.

I belong in my organization.

I have a say about what goes on in my organization.

People in my organization are good at influencing each another.

I feel connected to my organization.

I have a good bond with others in my organization.

Factor 2-Sense of Community Responsibility (SOC-R)

It is easy for me to put aside my own agenda in favor of the greater good of

When volunteers are needed by my organization, I feel like I should be one of the first to step up

I feel it is my duty to give to my organization without needing to receive

anything in return

I am always ready to help out people in my organization even if it creates

hardship for me

I often feel an obligation to do things that benefit my organization even if my

One of the best things I can do to improve my organization is to be of service to my co-workers

Factor 3-Organizational Citizenship Behaviors (OCBIs)

I help others who have been absent from work

$\begin{array}{ll}.64 & .63 \\ .66 & .65 \\ .58 & .53 \\ .67 & .66 \\ .69 & .68 \\ .69 & .65 \\ .58 & .54\end{array}$

I help others who have heavy workloads

I assist my supervisor with his/her work (when not asked)

I take time to listen to co-workers problems and worries

I go out of my way to help new employees

I take a personal interest in other employees

I pass along information to other coworkers

Factor 4-Organizational Citizenship Behaviors (OCBOs)

My attendance at work is above the norm

I give advance notice when I am unable to come to work

I take undeserved work breaks (R)

I spend a great deal of time with personal phone conversations ( $R$ )

I complain about insignificant things at work $(\mathrm{R})$

I conserve and protect organizational property

I adhere to informal rules designed to maintain order

Factor 5-Psychological Well-Being (GHQ-12)

I have been feeling unhappy and depressed

I constantly feel under strain

I have been losing confidence in myself

I have been feeling reasonably happy $(\mathrm{R})$

I have lost sleep over worry

I am able to concentrate $(\mathrm{R})$

I have been thinking of myself as worthless

I have been able to face problems (R)

I am able to enjoy day-to-day activities (R)

I feel capable in making decisions $(\mathrm{R})$

I feel that I can't overcome difficulties

I feel like I am playing a useful part in things (R)

Note. $\mathrm{CFA}=$ confirmatory factor analysis; $\mathrm{SE}=$ standardized estimates; $\mathrm{SE}$ with $\mathrm{CLF}=\mathrm{SE}$ with common latent factor; $\mathrm{SOC}=$ sense of community; SOC-R = sense of community responsibility; $\mathrm{OCB}=$ organizational citizenship behavior; OCBI = OCB directed toward individuals; OCBO = OCB directed toward organizations GHQ-12 = General Health Questionnaire.

Significant estimate deviations from model without common latent factor are in bold $(>.2)$. 
Table 2. Descriptive Statistics and Correlations for Major Study Variables

\begin{tabular}{|c|c|c|c|c|c|c|c|}
\hline Variable & $M$ & $S D$ & 1 & 2 & 3 & 4 & 5 \\
\hline 1. SOC & 5.10 & 1.23 & - & & & & \\
\hline 2. SOC-R & 5.09 & 0.99 & .378 & - & & & \\
\hline 3. OCBI & 6.07 & 0.63 & .292 & .487 & - & & \\
\hline 4. OCBO & 6.33 & 0.59 & .172 & .356 & .422 & - & \\
\hline 5. Psychological well-being & 5.57 & 0.91 & .393 & .290 & .358 & .327 & 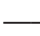 \\
\hline
\end{tabular}

Note. $\mathrm{M}=$ mean; $\mathrm{SD}=$ standard deviation; $\mathrm{SE}=$ standardized estimate; $\mathrm{SOC}=$ sense of community; $\mathrm{SOC}-\mathrm{R}=$ sense of community responsibility; $\mathrm{OCB}=$ organizational citizenship behavior; $\mathrm{OCBI}=\mathrm{OCB}$ directed toward individuals; $\mathrm{OCBO}=\mathrm{OCB}$ directed toward organizations.

$\mathrm{N}=369$. All correlations significant at $\mathrm{p}<.001$.

feel responsible. Moreover, participants frequently reported engaging in OCBs toward the organization and its members. Finally, respondents reported that their psychological wellbeing was generally high. A Pearson's correlation showed that SOC and SOC-R exhibit a moderate significant positive relationship $(\mathrm{r}=.378, \mathrm{p}<.001)$. This correlation supports the notion that both SOC and SOC-R tap into a common phenomenon related to the experience of community; however, the moderately low correlation suggests that responsibility and resource aspects of that experience are distinct. This finding in combination with the results of the CFA measurement model appear to lend support for $\mathrm{H} 1$ that SOC and SOC-R are unique constructs.

Moreover, both SOC and SOC-R showed a significant bivariate correlation to psychological well-being, but SOC demonstrated a stronger correlation $(\mathrm{r}=.393, \mathrm{p}<.001)$ compared to SOC-R $(\mathrm{r}=.290, \mathrm{p}<.001)$. Both SOC and SOC-R also were significantly correlated to OCBs, but SOC-R showed stronger correlations $(r=.487, p<.001$ for OCBI; $\mathrm{r}=.356, \mathrm{p}<.001$ for OCBO $)$ compared to SOC $(\mathrm{r}=.292, \mathrm{p}<001$ for OCBI; $\mathrm{r}=.172$, $\mathrm{p}<001$ for $\mathrm{OCBO}$ ). These two results provide initial impressions that are consistent with $\mathrm{H} 2$ and $\mathrm{H} 3$. Finally, OCBs were moderately and positively correlated with each other $(\mathrm{r}=.422, \mathrm{p}<001)$, and this was also true for psychological well-being and OCBs $(\mathrm{r}=$ $.358, \mathrm{p}<.001$ for OCBI; $\mathrm{r}=.327, \mathrm{p}<.001$ for OCBO).

\section{Tests of Major Hypotheses}

Next, several hypotheses were tested using structural equations modeling (SEM) in IBM SPSS Amos (version 21) to determine if SOC and SOC-R predicted outcomes in accordance with theory development in the literature. Direct effects were assessed for SOC and SOC-R on psychological well-being (see Table 3). Consistent with hypothesis 2, SOC exhibited a slightly higher direct effect compared to SOC-R, although both constructs were significant. Next, to determine if the direct effects were significantly different, two path models were compared. The first model freely estimated the coefficients of SOC and SOC-R, and the second model constrained the coefficients to be equal. A chi-square difference test $\left(\mathrm{X}^{2}=3.229, \mathrm{p}=.072\right)$ showed that the models (and thus the coefficients) approached a statistical difference from each other. These results lend some support for $\mathrm{H} 2$ by indicating that SOC appears to be a slightly better predictor of well-being relative to SOC-R.

Direct effects were assessed for SOC and SOC-R on OCBOs and OCBIs (see Table 3). Consistent with H3, SOC-R showed a significantly higher direct effect $\left(\mathrm{X}^{2}=7.653\right.$, $\mathrm{p}=.001$ and $\left.\mathrm{X}^{2}=4.665, \mathrm{p}=.001\right)$ compared to SOC on OCBOs and OCBIs, even though both constructs were statistically significant. 
Table 3. Direct Effects of SOC Versus SOC-R

\begin{tabular}{llc}
\hline Path & Direct effects & $X^{2}$ Difference test \\
Path & SE $p$ & $3.229, \mathrm{p}=.072$ \\
\hline SOC to PWB & $.257(.0001)$ & \\
SOC-R to PWB & $.225(.0001)$ & $7.653, \mathrm{p}<.001$ \\
SOC to OCBO & $.099(.008)$ & $4.655, \mathrm{p}<.001$ \\
SOC-R to OCBO & $.511(.0001)$ & $.469(.0001)$ \\
SOC to OCBI & $.565(.0001)$ & \\
SOC-R to OCBI & & \\
\hline
\end{tabular}

Note. $\mathrm{SE}=$ standardized estimate; $\mathrm{SOC}=$ sense of community; $\mathrm{PWB}=$ psychological well-being; $\mathrm{SOC}=$ sense of community; SOC-R = sense of community responsibility; $\mathrm{OCB}=$ organizational citizenship behavior; $\mathrm{OCBI}=\mathrm{OCB}$ directed toward individuals; $\mathrm{OCBO}=\mathrm{OCB}$ directed toward organizations.

Total $\mathrm{R}^{2}: \mathrm{PWB}, 12.7 \%(\mathrm{SOC}=7.7 \%$; SOC-R $=5.0 \%)$; OCBI, $58.8 \%(\mathrm{SOC}=21 \%$; SOC-R $=36.9 \%) ;$ OCBO, $28.0 \%$ $(\mathrm{SOC}=1.1 \% ; \mathrm{SOC}-\mathrm{R}=26.9 \%)$.

Mediation tests. Two mediation hypotheses were tested using SEM in IBM SPSS Amos (version 21) see Table 4. Tests of indirect effects of SOC for OCBOs and OCBIs via its influence on well-being were nonsignificant. Therefore, contrary to H4a, psychological well-being did not mediate the relationship between SOC and OCBs. Tests of indirect effects for SOC-R on psychological well-being via its influence on organizational citizenship were significant, indicating full mediation in accordance with H5a.

Moderation tests. Two moderation hypotheses were also tested using SEM in IBM SPSS Amos (version 21). In the first iteration, the interaction of SOC $\mathrm{x}$ well-being on OCBI was nonsignificant $(\mathrm{p}=.314)$, and the interaction was removed from the model (see Table 5 ). The model was run again, and the interaction of SOC $\mathrm{x}$ well-being on OCBO was significant $(\mathrm{p}=.029)$. Model fit was excellent $\left(\mathrm{X}^{2}=.972, \mathrm{p}=.324\right.$; CFI, .97; IFI, .980; RMSEA, $.022)$. Next, the interaction of SOC $x$ well-being on OCBO was graphed (see Figure 2). The visual representation of the interaction shows a very minimal moderation effect of psychological well-being on OCBO. As psychological well-being increases, the relationship between SOC and OCBOs slightly increases. In summary, no moderation exists for OCBIs and minimal moderation exists for OCBOs. H4b was partially confirmed.

Table 4. Mediation Effects of Psychological Well-Being and OCBs

\begin{tabular}{|c|c|c|}
\hline \multirow[t]{2}{*}{ Path } & Direct effects & \multirow{2}{*}{$\begin{array}{c}\text { Indirect effects } \\
\text { SE } p\end{array}$} \\
\hline & $S E \quad p$ & \\
\hline SOC - PWB - OCBO & $.099(.008)$ & $\begin{array}{l}.079(.343) \\
\text { No mediation }\end{array}$ \\
\hline SOC - PWB - OCBI & $.469(.0001)$ & $\begin{array}{l}.036(.481) \\
\text { No mediation }\end{array}$ \\
\hline SOC-R - OCBO - PWB & $.225(.0001)$ & $\begin{array}{c}.176(.0001) \\
\text { Full mediation }\end{array}$ \\
\hline SOC-R - OCBI - PWB & $.225(.0001)$ & $\begin{array}{l}.147(.0001) \\
\text { Full mediation }\end{array}$ \\
\hline
\end{tabular}

Note. $\mathrm{SE}=$ standardized estimate; $\mathrm{SOC}=$ sense of community; $\mathrm{PWB}=$ psychological well-being; $\mathrm{SOC}=$ sense of community; SOC-R = sense of community responsibility; $\mathrm{OCB}=$ organizational citizenship behavior; $\mathrm{OCBI}=\mathrm{OCB}$ directed toward individuals; $\mathrm{OCBO}=\mathrm{OCB}$ directed toward organizations. 
Table 5. Moderation Effects of Psychological Well-Being and OCBs

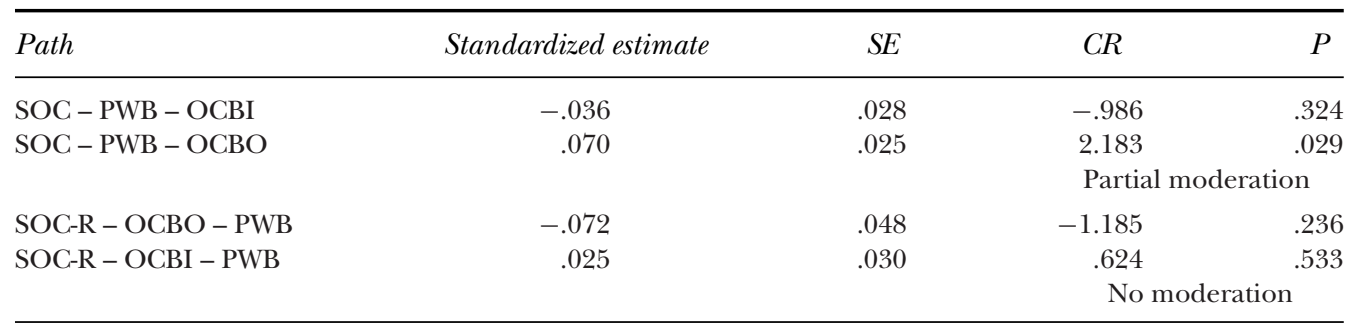

Note. $\mathrm{SE}=$ standardized estimate; $\mathrm{CR}=$ critical ratio; $\mathrm{SOC}=$ sense of community; $\mathrm{SOC}-\mathrm{R}=$ sense of community responsibility; $\mathrm{PWB}=$ psychological well-being; $\mathrm{OCB}=$ organizational citizenship behaviors; $\mathrm{OCBI}=\mathrm{OCB}$ directed toward individuals; $\mathrm{OCBO}=\mathrm{OCB}$ directed toward organizations.

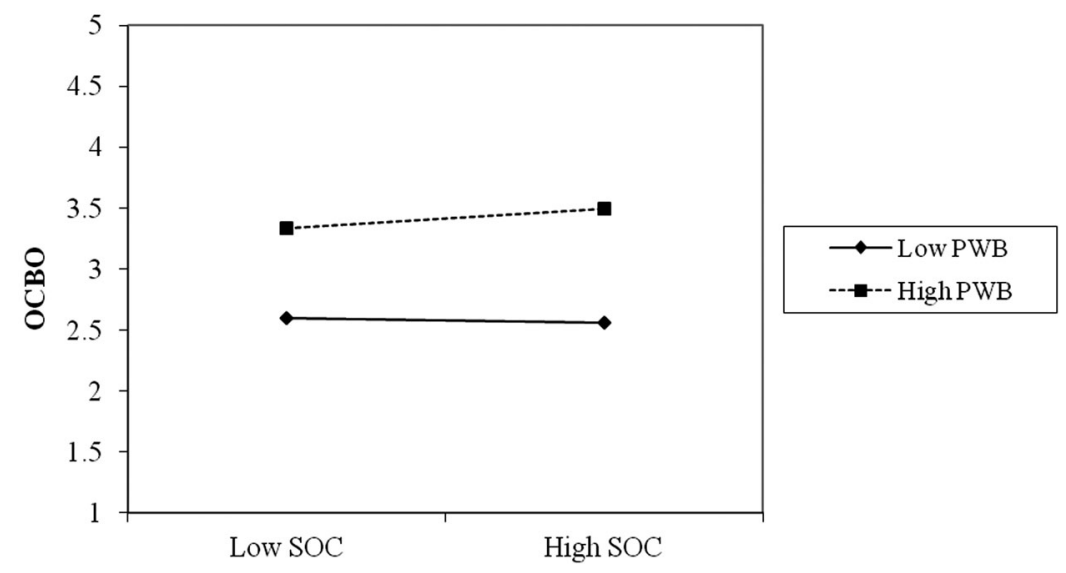

Figure 2. Moderation of psychological well-being on SOC-OCBO relationship.

Last, we examined the possibility of moderation of OCBs on the relationship between SOC-R and well-being (H5b). Results did not find evidence of significant moderation for either OCBOs or OCBIs. Therefore, OCBs did not moderate the relationship between SOC-R and psychological well-being. Final model fit was excellent $\left(\mathrm{X}^{2}=.895, \mathrm{p}=.408\right.$; CFI, .98; IFI, .99; RMSEA, .015). H5b was not confirmed.

\section{DISCUSSION}

The validation of the community experience framework in a single organizational setting makes an important contribution to the literature in its efforts to understand the role of community in organizational settings. This study provides the first empirical investigation into the differential predictive capacities of resource and responsibility aspects to the experience of community in understanding outcomes of well-being and organizational citizenship in workplace contexts. This work advances theory by clarifying the mechanisms and relationships by which responsibility and resource aspects of community connect to important employee outcomes. Overall, the findings supported the basic propositions of the community experience framework and demonstrated its applicability to the workplace context. 
Findings were remarkably consistent with the Nowell and Boyd's (2014) collaborative network study in demonstrating that SOC and SOC-R are separate and unique constructs that have the ability to predict employee psychological well-being and community engagement outcomes. In addition, the data showed that both SOC and SOC-R had a significant unique effect in predicting psychological well-being, but SOC was a slightly better predictor of well-being compared to SOC-R. Although this finding was consistent with the Nowell and Boyd (2010) model, these factors approached significance only as distinct predictors of well-being and, in total, were able to account for a modest $12.7 \%$ of the variance of psychological well-being. The present findings suggest that resource and responsibility aspects of the experience of community show better additive effects in predicting psychological well-being than individual discriminant prediction. Although SOC appears to be able to predict multiple measures of psychological well-being (job satisfaction vs. a measure of psychological distress), future research should continue to investigate and clarify the capacity of SOC and SOC-R in predicting various states of psychological well-being.

In contrast, SOC-R appeared to consistently predict organizational citizenship better than SOC. These findings provide additional empirical support for the propositions put forth by Nowell and Boyd (2010) that a values-based SOC-R would be a stronger driver of behavioral action taken on behalf of an organization and/or in support of its members. An additional finding is that, in general, community constructs were better able to predict OCBIs compared to OCBOs $(58.8 \%$ vs. $28 \%$ total variance explained, respectively). This is an interesting finding and may relate to the fact that the development of a community experience tends to occur within proximal relationships to other individuals at work compared to the entirety of the organization, which is more distal to the action of community development within organizations. For example, performing OCBIs to help coworkers might require the individual to pay attention to coworker needs, provide personal suggestions, engage in direct one-on-one interaction with the coworker, and handle potential resentment that could arise if the helping behavior was ultimately unwanted (Neilsen et al., 2012).

Several exploratory mediation and moderation tests also revealed some interesting findings that extend our knowledge in this area. Specifically this study found some evidence that the relationship of SOC to organizational citizenship is influenced by increased well-being. Although the results indicated that psychological well-being does not mediate the relationship between SOC and any community engagement behaviors, a partial moderation effect was found for well-being on OCBOs. The effect of SOC on OCBOs was also very weak, and thus it is reasonable to conclude that psychological well-being, as measured in the present study, does not affect the relationship between SOC and community engagement in any meaningful way. Again, future research should continue to investigate and monitor the capacity for well-being measures to affect the relationship between SOC and behavioral engagement in organizations.

For SOC-R, Nowell and Boyd (2010) stated that responsibility aspects of community experiences develop as a function of the interaction between the organizational context and the belief systems of employees as they enter and work in the organization. Consistent with the logic of person-environment fit (e.g., Kristof-Brown \& Guay, 2011), if the organization provides a context in which a sense of responsibility can flourish, then an employee would be expected to increase engagement in that setting. Once engaged, the psychological well-being of the individual would be stimulated because one's actions would be congruent with one's beliefs (Festinger, 1964). Findings are consistent with this theory: The relationship between feelings of community responsibility and 
psychological well-being is mediated by taking action to enhance the community, thereby bringing cognitive identity and action into alignment.

In addition to testing theory, the findings showed that both SOC and SOC-R are predictive of key outcomes in a workplace setting. This is an important finding because it emphasizes that community constructs are applicable in organizational settings (Boyd, 2014; Boyd \& Angelique, 2007, 2002) and demonstrates that community constructs likely have significant exportation capabilities in work contexts. In addition, from an organizational perspective, these findings add an important construct to the field of management (Boyd \& Nowell, 2014) and show managers that SOC and SOC-R are factors that are important in the milieu of organizational life.

SOC-R, in particular, appears to have widespread potential to those who are interested in stimulating a workforce that is engaged and responsible to the needs of their coworkers and the organization. Cohen (2007) argues that employees enter organizations with normative predispositions toward social responsibility. When supported by an organization and management culture that enhances employee social responsibility values, prosocial behavior can result. Thus, when organizations congruently stimulate employee responsibility values, employees will likely engage in OCBs.

The present findings are consistent with Smith, Organ, and Near (1983), who confirmed that OCB is an exhibition of prosocial disposition propensity; Finkelstein (2006), who indicated that employees' prosocial value can influence their OCB; and Grant and Mayer (2009), who found that individual's prosocial motivation is predictive of citizenship behavior (such as voice). However, the present findings are distinctive from this research because they demonstrate the connection between a sense of responsibility and a particular organizational referent while situated within the referent. Previous research focused on prosocial dispositions that are within the individual as they enter the organization. However, what is not known at this time is what contextual factors serve to evoke a sense of responsibility for a given workplace. This will be an important area for future research.

Although not directly assessed in the present study, the findings may lend credence to the notion that a SOC-R can occur as a function of organizational context and managerial antecedents. This is a promising direction for future research because OCB scholars appear to have achieved a general consensus that OCB is the outcome of the interaction between individuals and organizational contextual variables. For example, Lavelle, Rupp, and Brockner (2007) noted that when employees perceive organizational justice and high quality leader-member exchange relationships, they actively engage in OCB on the basis of a positive reciprocity norm. Although the notion of SOC-R does not rely on reciprocity and social exchange theory logics, it certainly is possible that SOC-R can be stimulated by organizational antecedents. Finally, considering that OCB consistently correlates with employee performance, retention, and other important organizational outcomes (Podsakoff, Whiting, Podsakoff, \& Blume, 2009), SOC-R holds promise as a factor that may influence additional critical employee and organizational outcome factors. This area of inquiry has the potential to bear important fruit for scholars and managers in the future.

The present work also indicates that managerial efforts to make the workplace a setting that meets workers social-psychological needs for inclusion, influence, and membership can have a positive effect on worker's psychological health. Psychological health of employees is an area of concern for organizational scholars and practicing managers alike. This suggests an opportunity for managers to create greater opportunities for affiliation, influence, and connection needs of employees through an array of 
management interventions. And as need fulfillment resources are provided by thoughtful organizational design, employees will psychologically benefit and behaviorally act in ways that advance and satisfy their needs and the goals of the organization. The present findings are consistent with Wilson, DeJoy, Vandenberg, Richardson, and McGrath (2004), who showed that health and well-being are directly affected by employee perceptions of their organization and employee attitudes toward their workplace climate. In addition, they are consistent with Rego, Souto, and Cunha (2009), who demonstrated that a spirit of camaraderie among workers is predictive of affective well-being.

Moreover, the findings are consistent with Judge and his colleagues (Judge \& Bono, 2001; Judge, Locke, Durham, \& Kluger, 1998), who found that psychological perceptions of work were one of the primary causes of job satisfaction (one of the most common measures of employee well-being in the organizational literature), and Brooke, Russell, and Price (1988), who claimed that job satisfaction reflects an individual's general attitude toward the job, stemming from the gratification of needs and wants. Because job satisfaction and psychological well-being consistently predict employee turnover (Griffeth, Hom, \& Gaertner, 2000; Kinicki, McKee-Ryan, Schriesheim, \& Carson, 2002; Price, 1977, 2001; Wright, \& Bonett, 2007) and are somewhat related to employee performance (Baptiste, 2008; Bowling, 2007; Judge \& Bono, 2001), the present findings show promise for future explorations into the relationship between SOC and important individual and organizational outcomes.

\section{Limitations}

Interpretation of the findings from this study must take into account a few possible limitations. One limitation is that the cross-sectional nature of the data does not allow for causal inference. However, in organizational field settings, which are important spaces for organizational research, it is uncommon for the researcher to have the ability to manipulate independent variables to ascertain direct effects on dependent variables. The present study was designed to investigate relationships and prediction in a field setting where experiences of community could naturally develop without intervention of the researcher. With that said, this research agenda could benefit from future studies that explore community constructs in controlled laboratory settings that mimic organizational conditions, via quasi-experimental studies in field settings or in more naturalistic field settings that involve longitudinal research in which fewer extraneous factors could be controlled. It should be noted that there are benefits as well as difficulties in executing these types of studies, and that corroboration across various studies that employ different research methods will likely be the necessary course to advancing this area of research.

Second, the measures in the study were based on a single method of data collection. In this regard, we implemented procedural remedies including counterbalancing the order of survey items and refinement of scale items. Moreover, we ran appropriate statistical remedies for potential common-method bias, including CFA techniques and the computation of common latent factor analysis, which resulted in the use of common method bias adjusted composites. Because the pattern of findings is consistent with both the theoretical propositions of the community experience framework (Nowell \& Boyd, 2010) and the community collaboratives study by Nowell and Boyd (2014), our confidence in the present findings is increased. 


\section{Directions for Future Research}

With an eye to the future, the introduction and validation of the community experience framework to the workplace setting suggests several important directions for future research. The current research provides support for the idea that organizations are important community contexts. However, where a person works is not the only community context of importance to them. Indeed, people are nested in multiple community settings simultaneously. It is reasonable to assume that they will not feel equal levels of responsibility or community in all of them. Therefore, a future area of inquiry could evaluate how SOC and SOC-R vary across people nested within the same workplace and within individuals across organizational settings in which they are nested. The psychology behind where and how people identify the boundaries that define their perceived realms of community and responsibility is an interesting area for future research.

Moreover, if SOC is a driver of psychological well-being, and responsibility is a driver of organizational citizenship behavior and engagement with these variables leading to outcomes like turnover, absenteeism, and performance, then future studies should explore how managers can design workplace settings to evoke a SOC and SOC-R perceptions. Future work in this area will hopefully lead to prescriptions of how managers can build communities at work.

At the moment, the research agenda on community experiences in organizations needs to focus on validating the convergent validity of SOC and SOC-R factor structures and testing discriminant validity of these constructs on key employee and organizational outcomes. Once that has been clearly established, a next step will be to understand how SOC and SOC-R act in relation to established constructs in the field of management. Boyd and Nowell (2014) proposed that SOC and SOC-R are distinct concepts to organizational identity, organizational commitment, social capital, team cohesion, and psychological contracts. Empirical verification that SOC and SOC-R produce differential and useful prediction of important organizational and human outcomes compared to common management constructs will be an important step in future studies.

As this work continues, it is conceivable that enhancements to model development for a variety of psychological constructs can be achieved. This work could help to verify both antecedents and consequences of psychological constructs, as well as helping managers to determine how a series of psychological constructs can assist in producing healthy workplaces where employees thrive and at the same time produce significant outcomes for organizations.

\section{Conclusion}

In conclusion, the psychology that serves as the bedrock of an individual's SOC and SOC$\mathrm{R}$ for a community in an organizational context is new, yet it has significant theoretical and practical implications for organizational scholars and practicing managers. Moreover, this study provides an important contribution to advancing our understanding of the factors that drive members' willingness to give of themselves toward collective aims in workplace contexts. Finally, the present study advances our understanding of the predictive capacities of SOC and SOC-R on important human and organizational outcomes. The study shows that they are likely distinct concepts which have separate etiologies and function in determining how members experience and engage in organizational settings. 


\section{REFERENCES}

Albanesi, C., Cicognani, E., \& Zani, B. (2007). Sense of community, civic engagement and social well-being in Italian adolescents. Journal of Community \& Applied Social Psychology, 17(5), $387-406$.

Anseel, F., Lievens, F., Schollaert, E., \& Choragwicka, B. (2010). Response Rates in Organizational Science, 1995-2008: A Meta-analytic Review and Guidelines for Survey Researchers. Journal of Business and Psychology, 25, 335-349.

Ashmos, D. \& Duchon, D. (2000). Spirituality at work: A conceptualization and measure. Journal of Management Inquiry, 9(2), 134-145.

Baptiste, N. R. (2008). Tightening the link between employee well-being at work and performance. Management Decision,46(2), 284-309.

Barczak, G. M., Smith, C., \& Wilemon, D. (1987). Managing large-scale organizational change. Organizational Dynamics, 16(2), 22-35.

Block, P. (2008). Community: The structure of belonging. San Francisco: Berrett-Koehler.

Bowling, N. (2007). Is the job satisfaction-job performance relationship spurious? A meta-analytic examination. Journal of Vocational Behavior, 71, 167-185.

Boyd, N. (2014). A 10-year retrospective of organization studies in community psychology: Content, theory, and impact. Journal of Community Psychology, 42(2), 237-254.

Boyd, N., \& Angelique, H. (2007). Resuming the dialogue on organization studies andcommunity psychology: An introduction to the special issue. Journal of Community Psychology, 35(3), 281-285.

Boyd, N., \& Angelique, H. (2002). Rekindling the discourse: Organization studies in community psychology. Journal of Community Psychology, 30(4), 325-348.

Boyd, N. \& Nowell, B. (2014). Psychological sense of community: A new construct for the field of management. Journal of Management Inquiry, 23(2), 107-122.

Brodsky, A. E., O’Campo, P. J., \& Aronson, R. E. (1999). PSOC in community context: Multi-level correlates of a measure of psychological sense of community in low-income, urban neighborhoods. Journal of Community Psychology, 27(6), 659-679.

Brooke, P., Russell, P., \& Price, J. (1988). Discriminant validation of measures of job satisfaction, job involvement and organizational commitment. Journal of Applied Psychology, 73, 139-145.

Brytting, T., \& Trollestad, C. (2000). Managerial thinking on value-based management. International Journal of Value-Based Management, 13, 55-77.

Burroughs, S. M., \& Eby, L. T. (1998). Psychological sense of community at work: A measurement system and explanatory framework. Journal of Community Psychology, 26(6), 509-532.

Chavis, D. M., Lee, K. S., \& Acosta J. D. (2008). The sense of community (SCI) revised: The reliability and validity of the SCI-2. Paper presented at the 2nd International Community Psychology Conference, Lisboa, Portugal.

Chioneso, N. A., \& Brookins, C. C. (2013). Coming to get and needing to keep: participation within a membership association for Black scholars. Journal of Black Psychology, 41 (1), 49-74.

Cohen, A. (2007). Commitment before and after: An evaluation and reconceptualization of organizational commitment. Human Resource Management Review, 17, 336-354.

Coyle-Shapiro, J. (2002). Exploring reciprocity through the lens of the psychological contract: Employee and employer perspectives. European Journal of Work and Organizational Psychology, 11(1), 69-86.

Cunha, M. P., Rego, A., \& Vaccaro, A. (2014). Organizations as human communities and internal markets: Searching for duality. Journal of Business Ethics, 120(4), 441-455.

Davidson, W. B., \& Cotter, P. R. (1991). The relationship between sense of community and subjective well-being: A first look. Journal of Community Psychology, 19(3), 246-253. 
Dessler, G. (1999). How to earn your employees' commitment. Academy of Management Executive, $13(2), 58-67$.

Festinger, L. (1964). Conflict, decision, and dissonance (Vol. 3), Palo Alto: Stanford University Press.

Finkelstein, M. A. (2006). Dispositional predictors of organizational citizenship behavior: Motives, motive fulfillment, and role identity. Social Behavior and Personality, 34, 603616.

Goldberg, D. P. \& Williams, P. (1988). A user's guide to the General Health Questionnaire. Windsor, UK: NFER-Nelson.

Grant, A., \& Mayer, D. M. (2009). Good soldiers and good actors: Prosocial and impression management motives as interactive predictors of affinitive citizenship behavior. Journal of Applied Psychology, 94, 900-912.

Griffeth, R. W., Hom, P. W., \& Gaertner, S. (2000). A meta-analysis of antecedents and correlates of employee turnover: Update, moderator tests, and research implications for the next millennium. Journal of Management, 26, 463-488.

Hughey, J., Speer, P. W., \& Peterson, N. A. (1999). Sense of community in community organizations: Structure and evidence of validity. Journal of Community Psychology, 27(1), 97113.

Judge, T. A., \& Bono, J. E. (2001). Relationship of core self-evaluations traits-Self-esteem, generalized self-efficacy, locus of control, and emotional stability-With job satisfaction and job performance: A meta-analysis. Journal of Applied Psychology, 86, 80-92.

Judge, T. A., Locke, E. A., Durham, C. C., \& Kluger, A. N. (1998). Dispositional effects on job and life satisfaction: The role of core evaluations. Journal of Applied Psychology, 83, 17-34.

Kets de,Vries, M. F. R. (2001). Creating authentizotic organizations: Well-functioning individuals in vibrant companies.Human Relations, 54(1), 101-111.

Kinicki, A. J., McKee-Ryan, F. M., Schriesheim, C. A., \& Carson, K. P. (2002). Assessing the construct validity of the job descriptive index: A review and meta-analysis. Journal of Applied Psychology, $87,14-32$.

Klein, K. J., \& D’Aunno, T. A. (1986). Psychological sense of community in the workplace. Journal of Community Psychology, 14(4), 365-377.

Lavelle, J. J., Rupp, D. E., \& Brockner, J. (2007). Taking a multifoci approach to the study of justice, social exchange, and citizenship behavior: The target similarity model. Journal of Management, 33, 841-866.

Lesage, F. X., Martens-Resende, S., Deschamps, F., \& Berjot, S. (2011). Validation of the General Health Questionnaire (GHQ-12) adapted to a work-related context. Open Journal of Preventive Medicine, 1(2), 44-48.

McBride, J. L. (2006). Effective work relationships: A vital ingredient in your practice. Family Practice Management, Nov/Dec, 45-46.

Miers, R., \& Fisher, A. T. (2002). Being church and community Psychological Sense of Community (pp. 141-160). New York: Springer.

Milliman, J., Czaplewski, A. J., \& Ferguson, J. (2003). Workplace spirituality and employee work attitudes: An exploratory empirical assessment. Journal of Organizational Change Management, $16,426-447$.

Mintzberg, H. (2009). Rebuilding companies as communities. Harvard Business Review, July-August ,1-7.

Nowell, B., \& Boyd, N. (2010). Viewing community as responsibility versus resource: Deconstructing the theoretical roots of psychological sense of community. Journal of Community Psychology, $38,828-841$. 
Nowell, B., \& Boyd, N. (2011). Sense of community as construct and theory: Authors' response to McMillan. Journal of Community Psychology, 39(8), 889-893.

Nowell, B., \& Boyd, N. (2014). Sense of community responsibility in community collaboratives: Advancing a theory of community as resource and responsibility. American Journal of Community Psychology, 54, 229-242

Obst, P., Zinkiewicz, L., \& Smith, S. (2002). Sense of community in science fiction fandom, Part 1: Understanding sense of community in an international community of interest. Journal of Community Psychology, 30, 87-103.

Perkins, D., Florin, P., Rich, R., Wandersman, A., \& Chavis, D. (1990). Participation and the social and physical environment of residential blocks: Crime and community context American Journal of Community Psychology, 18(1), 83-115.

Peterson, N. A., Speer, P. W., \& McMillan, D. W. (2008). Validation of a brief sense of community scale: Confirmation of the principal theory of sense of community. Journal of Community Psychology, 36(1), 61-73.

Podsakoff, P. M., MacKenzie, S. B., Lee, J. Y., \& Podsakoff, N. P. (2003). Common method biases in behavioral research: A critical review of the literature and recommended remedies. Journal of Applied Psychology, 88(5), 879-903.

Podsakoff, N. P., Whiting, S. W., Podsakoff, P. M., \& Blume, B. D. (2009). Individual- and organizational-level consequences of organizational citizenship behaviors: A meta-analysis. Journal of Applied Psychology, 94, 122-141.

Pretty, G. M. (1990). Relating psychological sense of community to social climate characteristics. Journal of Community Psychology, 18(1), 60-65.

Pretty, G. M., Conroy, C., Dugay, J., Fowler, K., \& Williams, D. (1996). Sense of community and its relevance to adolescents of all ages. Journal of Community Psychology, 24(4), 365-379.

Pretty, G. M., \& McCarthy, M. (1991). Exploring psychological sense of community among women and men of the corporation. Journal of Community Psychology, 19(4), 351-361.

Prezza, M., \& Pacilli, M. G. (2007). Current fear of crime, sense of community and loneliness in Italian adolescents: The role of autonomous mobility and play during childhood. Journal of Community Psychology, 35, 151-170.

Prezza, M., Pacilli, M. G., Barbaranelli, C., \& Zampatti, E. (2009). The MTSOCS: A multidimensional sense of community scale for local communities. Journal of Community Psychology, 37, 305326.

Price, J. L. (1977). The study of turnover. Ames, IA: The Iowa State Press.

Price, J. L. (2001). Reflection on the determinants of voluntary turnover. International Journal of Manpower, 22, 600-621.

Rego, A. \& Cunha, M. P. (2008). Workplace spirituality and organizational commitment: An empirical study. Journal of Organizational Change Management, 21(1), 53-75.

Rego, A., \& Cunha, M. P. (2007). Perceptions of authentizotic climates and employee happiness: Pathways to individual performance? Journal of Business Research, 61, 739-752.

Rego, A., Cunha, M., \& Souto, S. P. (2007). Workplace spirituality, commitment, and self-reported individual performance: An empirical study. Management Research: The Journal of the Iberoamerican Academy of Management, 5, 163-183.

Rego, A., Souto, S., \& Cunha, M. P. (2009). Does the need to belong moderate the relationship between perceptions of spirit of camaraderie and employees' happiness? Journal of Occupational Health Psychology, 14(2), 148-164.

Rowley, J., Kupiec-Teaham, B., \& Leeming, E. (2007). Customer community and co-creation: A case study. Marketing Intelligence \& Planning, 25, 136-146.

Royal, M. A., \& Rossi, R. J. (1996). Individual-level correlates of sense of community: Findings from workplace and school. Journal of Community Psychology, 24(4), 395-416. 
Smith, C. A., Organ, D. W., \& Near, J. P. (1983). Organizational citizenship behavior: Its nature and antecedents. Journal of Applied Psychology, 68, 653-663.

Sonn, C. (2002). Immigrant adaptation: Understanding the process through sense of community. In A. Fisher \& C. Sonn (Eds.), Psychological sense of community: Research, applications, and implications (pp. 205-222). New York: Plenum.

Speer, P. W., Peterson, N. A., Armstead, T. L., \& Allen, C. T. (2013). The influence of participation, gender and organizational sense of community on psychological empowerment: The moderating effects of income. American Journal of Community Psychology, 51 (1-2), 103-113.

Williams, L. J., \& Anderson, S. E. (1991). Job satisfaction and organizational commitment as predictors of organizational citizenship and in-role behaviors. Journal of Management, 17(3), 601-617.

Wilson, M. G., DeJoy, D. M., Vandenberg, R. J., Richardson, H. A., \& McGrath, A. L. (2004). Work characteristics and employee health and well-being: Test of a model of healthy work organization. Journal of Occupational and Organizational Psychology, 77, 565-588.

Wright, T. A., \& Bonett, D. G. (2007). Job satisfaction and psychological well-being as nonadditive predictors of workplace turnover. Journal of Management, 33(2), 141-160.

Zani, B., \& Cicognani, E. (2012). Sense of community in the work context. A study on members of a co-operative enterprise. Global Journal of Community Psychology Practice, 3(4), 1-8. 